\title{
Anika Bethan, Napoleons Königreich Westphalen - Lokale, deutsche und europäische Erinnerungen
}

Paderborn : Schöningh (Die Revolutions- und Napoleonischen Kriege in der europäischen Erinnerung, 2), 2012, 365 p., $48 €$

\section{Boris Klein}

\section{OpenEdition}

\section{Journals}

Édition électronique

URL : http://journals.openedition.org/ifha/8170

DOI : $10.4000 /$ ifha. 8170

ISSN : 2198-8943

\section{Éditeur}

IFRA - Institut franco-allemand (sciences historiques et sociales)

\section{Référence électronique}

Boris Klein, « Anika Bethan, Napoleons Königreich Westphalen - Lokale, deutsche und europäische Erinnerungen », Revue de l'IFHA [En ligne], Date de recension, mis en ligne le 14 avril 2015, consulté le 22 septembre 2020. URL : http://journals.openedition.org/ifha/8170 ; DOI : https://doi.org/10.4000/ ifha. 8170

Ce document a été généré automatiquement le 22 septembre 2020.

CIFHA 


\section{Anika Bethan, Napoleons Königreich Westphalen - Lokale, deutsche und europäische Erinnerungen}

Paderborn : Schöningh (Die Revolutions- und Napoleonischen Kriege in der europäischen Erinnerung, 2), 2012, 365 p., $48 €$

\section{Boris Klein}

Né au lendemain de la paix de Tilsit en 1807 , le royaume de Westphalie est constitué par Napoléon pour son jeune frère Jérôme à partir de plusieurs territoires distincts de l'Allemagne du nord, essentiellement le duché de Brunswick, l'Électorat de Hesse et les évêchés de Paderborn et d'Osnabrück. Gouverné depuis Kassel, le nouvel État reçoit une constitution qui bouleverse profondément l'ordre féodal en vigueur, et l'Empereur entend explicitement en faire une construction modèle aux yeux des Allemands et du reste de l'Europe soumise. C'est d'ailleurs souvent sous cet aspect, une tentative pour établir une monarchie éclairée et satellisée, que le royaume a retenu l'attention des historiens. L'ouvrage d'A. Bethan présente l'intérêt de tenter une autre approche, en s'inscrivant dans la série d'études menées depuis une dizaine d'années et consacrées à l'impact de la Révolution et des guerres napoléoniennes sur la mémoire européenne et la construction des identités nationales. En se demandant quand et dans quel contexte la mémoire du défunt royaume a refait surface entre 1813 et 1871, l'auteur cherche à découvrir dans quelle mesure la brève occupation française dans le nord de l'Allemagne a contribué à forger des groupes et des identités, en lien avec des processus de politisation ou simplement l'émergence de sentiments collectifs nouveaux.

L'analyse progresse ainsi en trois parties, consacrées chacune à un groupe distinct. La première se penche sur les soldats, enrôlés dans la Grande Armée pour participer notamment aux combats en Espagne et à la campagne de Russie. Dans le contexte de la restauration des anciennes dynasties et frontières, et du rejet de l'ancien occupant, les vétérans font logiquement l'objet d'une tentative de négation de leur passé par les autorités; grâce à des cas particuliers et à des archives juridiques illustrant les réclamations et démarches menées au cours des décennies qui ont suivi 1813, A. B. 
montre pourtant comment ces anciens combattants sont particulièrement visibles et pris en charge à l'échelle locale, et combien ils entretiennent le souvenir de leurs périples guerriers. Très proche de celui des militaires, le destin des fonctionnaires est abordé dans la seconde partie. Là encore, l'auteur s'appuie sur la reconstitution de cas et de parcours singuliers, et montre comment les autorités ont oscillé entre la volonté de punir certains hauts serviteurs de l'État et la nécessité de conserver un personnel qualifié. Toujours en explorant les archives juridiques ou les lettres de certains personnages, A. B. souligne que certains de ces administrateurs ont été séduits par les principes libéraux apportés par les conquérants ; plus intéressante encore est la façon dont beaucoup ont justifié leur "collaboration " après 1807, arguant notamment de leur devoir de fidélité et de service envers la patrie ou le peuple, plus qu'envers les princes contraints à l'exil. Enfin, la troisième partie se penche sur ceux qui ont tenté de résister et de se révolter contre le pouvoir du roi Jérôme. Et là encore, l'auteur expose avec finesse la façon dont les gouvernements autoritaires issus de la restauration après 1815 ont peiné à s'approprier et à gérer le souvenir de ces révoltes, souvent liées à une politisation croissante d'une partie de la population - et au rejet de l'autorité.

Ce travail de thèse mené entre 2006 et 2010 souligne donc utilement la longue portée dans les mémoires de l'occupation et des réformes napoléoniennes, de même que la difficulté sous la restauration et dans les différents états revenus à leurs anciennes frontières de porter un regard sur ce passé complexe - et sur ce dernier point d'ailleurs, les changements d'échelles géographiques et la présentation des différentes attitudes selon les états concernés (Prusse, Brunswick ou Hesse) sont effectués avec clarté. Quelques regrets subsistent cependant: puisque l'étude se penche sur la construction de groupes sociaux et identitaires, il est dommage que l'enquête ne soit parfois pas davantage poussée sur ce terrain; dans le cas des hauts fonctionnaires, l'étude précise des réseaux familiaux ou autres aurait peut-être permis de mieux éclairer la diversité des carrières et des destins. D'autre part, on peut regretter que les tentatives de croisement des regards historiographiques sur les différents points évoqués se bornent uniquement aux travaux anglais et français et n'adoptent pas une perspective plus européenne. La clarté du propos et les choix ambitieux de méthode font néanmoins de cette étude un jalon précieux dans le renouvellement actuel des études sur l'impact de la période napoléonienne tout au long du XIXe siècle.

INDEX

Index chronologique : Époque contemporaine

Thèmes : Histoire des états et des pouvoirs, Histoire sociale

\section{AUTEUR}

BORIS KLEIN

LabEx COMOD / LARHRA, Lyon 